\title{
Phenomenology method of making a place
}

\author{
Duc $\operatorname{Tran}^{1 *}$ \\ ${ }^{1}$ University of Architecture Ho Chi Minh City, 196 Pasteur st., Dist.3, Ho Chi Minh City, Vietnam
}

\begin{abstract}
The paper shows the concept of phenomenology originated from Edmund Husserl's contemplation of "I think, therefore I am." As the scientific method of consciousness, phenomenology relates to architecture via the phenomenological-self. The method concentrated on investigation and description, without prejudices. Living in the world, the phenomenological-self can be a being man, a perpetual man, a wandering man, or a sensory man. Places appear because these egos have projected them to in-between the Earth and Heaven. The selves rendered their dwelling by reflection, imagination, apperception, or sensation of the built environment. The site historicity impacted on making architecture as humans' embodiment. The influence can be either site conformation or humans force as traditional culture. Both are the primary objects of the phenomenology method that is taken shape in four steps, from Husserl's five phases for pure knowledge. Applying those paces in making a place, designer and students keep off their prejudices to produce a pure phenomenological architecture meaningful and articulatory to its surrounding.
\end{abstract}

\section{Introduction}

Humans have engaged nature as an ideal paradigm of form and function since the beginning of time to express their physical and mental. Architecture as humans' embodiment may be seen to constitute an organic relationship with nature in any climatic, cultural, and social condition. Though often referent from nature, architectural forms in various shapes and with different purposes have not been assimilated with their sites yet. Recently, some modern design movements have emerged, such as of biomorphic form and bio-mimicry. Unfortunately, these movements often fail to the totality and depth of their relationship to the natural, because their ways missed the essence and the connection of a dwelling in a place, or called genius loci.

Studies showed spirit of a place can be defined by means of phenomenology method that was originated from Edmund Husserl's philosophy of human experience. It is used to criticize humans' cognition to reach to the essence of things, when sensed or experienced, through investigation and description. The phenomenological discovery aims at to explore fundamental commonalities in which the crucial core of the phenomena is shown. It pays attention to phenomena specific cases that can provide universal features and qualities correctly to depict their appearance and meaning in the living world. Phenomenology method proposes exclusive steps to move towards objectivity, though the phenomenological world is

\footnotetext{
* Corresponding author: ductran@hawaii.edu
} 
perceived by humans' vision or other bodies, such as hearing, smelling, tasting, and touching. The method has a connection with architectural process because of man's design position as a being-Iin "critique of knowledge" (Lee Hardy, "Translator's Introduction," in Edmund Husserl: The Idea of Phenomenology, Trans. Lee Hardy (Netherlands: Kluwer Academic Publishers,2010,3.) to obtain the status of 'pure consciousness' (Ibid.,8) for achievement of the soul of place.

Many erudite scholars carried out scientific researches in the hope of perfectly translating phenomenology into architecture. They showed the relation between phenomenology and architecture and phenomenological experiences application to architecture design. Almost architectural forms sprung out the exploitation of nature poetics and materials. For all that, like modern forms, these forms appear with their meaning referent from semiotics and history, rather reference to existing models.

Furthermore, with the advent of digital technology, the emergence of emotional communication, unforeseen changes in social and political structures, a unity of form, function, and meaning is requested to articulate to its place with regards to site conformation and human experience. In other words, an architectural form is needed to result from the fitness between rationality and naturalness. To respond to the conditions and address the new architecture that adapts to these requirements, this paper purposes to provide a philosophical method for architectural practice through concretizing humans' culture and the built environment historicity.

\section{Literature review}

Fundamentally critical theory and phenomenology are two methodologies for the interpretation of "how architecture functions in the world." (Eran Neuman, "The Present State of Phenomenology in Architecture," in Invitation to ArchiPhen: Some Approaches and Interpretations of Phenomenology in Architecture, Ed. Iris Aravot and Eran Neuman (Villejuif Cedex, FR: Zeta Books,2009,10.). The former suggested a method for context analysis of utilitarian spaces under the consideration of culture, society, and power; differently, the latter concentrated on the way of practicing spirit of place such as light, shadow, landscape, materials, and space poetics.

Not existing alone, the method emerges along with other modern methods. Its position shows up clearly in the early 20th century and the first time present in architecture in 1950's. In fact, phenomenology has already rooted in each of our perspective and existed as reflection on our immanent subjectivity, that form our idea and the surrounding relation for analysis and interpretation of the world, according to Iris Aravot, on Invitation to Archiphen: Some Approaches and interpretations of Phenomenology in Architecture. Unlike philosophers' method heading toward transcendental experience for validly knowledgeable commonalities, phenomenology in architecture searches for historically specific understandings. Experiencing things or architecture via phenomenological ego leads the views of phenomenological sensation that are cultivated and developed in making architectural place, such as in Christian Norberg-Schulz's architecture, Juhani Palassma's architecture, Peter Zumthor's architecture, and Steven Holl's architecture. Also, phenomenology of geography and environment is emphasized to examine the essential relation among human, building, landscape, and place that forms the environmental design method sustainable as mentioned by David Seamon, “..., how phenomenological and similar qualitative approaches can lead to environmental understanding and design more in tune with our experiences and lives as human beings in the everyday world." (David Seamon, "Dwelling, Seeing, and Designing: An Introduction," in Dwelling, Seeing, and Designing: Toward a Phenomenological Ecology, Ed. David Seamon (Albany: State University of New York, 1993,2). 


\section{Materials and method}

To point out the phenomenology method that carries out translating culture and historicity to architecture, the paper returned and decoded the primary concept of phenomenology. The two books: Edmund Husserl: The Idea of Phenomenology translated and introduced by Lee Hardy (1999) and Cartesian Mediations: An introduction to phenomenology translated by Dorion Cairns, were used as the sources for the investigation. This research provided an underlying knowledge of the phenomenological principles for designing an architectural system by a transcendental ego. Next, this study sought for the evolution of the self in Martin Heidegger's "Building Dwelling Thinking" of Poetry, Language, Thought (2013), Merlau Ponty's Phenomenology of Perception, Juhani Palassma's The Eyes of Skin (2012), and Norberg-Schulz's Genius Loci: Towards a Phenomenology of Architecture (1991), for understanding the relationship between philosophical phenomenology and architectural phenomenology. Then, basing on harvested facts from these documents, the "Logical Argumentation" method was used to determine the phenomenology method in architecture. Finally, an example of studio project named "Worker Housing in Danang city, Vietnam" was shown to illustrate how the method translates aspects of culture and the built environment history of making a place.

\section{Results}

\subsection{The phenomenological self}

\subsubsection{A pure man}

The initial idea of phenomenology was put forward by Edmund Husserl in Cartesian Mediations: An introduction to phenomenology. Criticizing on "Cogito, ergo sum" (I think therefore I am), Husserl asserted Descarte's rational-empirical mind missed phenomenological ego. Because of relying on being ego or psychological ego on things, our experiences were held in the solipsism cage. Understanding of things based on sequenced presumptions that we have never known the ones' primary. In the Lecture II, on The Idea of phenomenology, Husserl started phenomenology by "how can the critique of knowledge establish itself?" (Edmund Husserl, "Lecture II," 23), and proposed no starting point for human beings' cognition, but predetermined (Ibid.), which relates to judge and bias. $\mathrm{He}$ suggested phenomenology method released our thinking from prejudiced deductions, to attain objective and genuine knowledge or things essence, when we "perceive, imagine, judge, and infer" (Ibid). In other words, phenomenology is the scientific attitude on consciousness for description, executed by a phenomenological self with the aim of criticism on things experiences. On the way of the essentially understanding things, the phenomenological self goes through five stages: carrying out the critique of knowledge, status of knowing subject as an absolute certainty, diverse forms of objectivity, forms of interconnection, and forms of genuine appearance. In the process, the self plays a role as a centralizer that investigates both his immanence and external.

\subsection{2 $A$ being self}

As humans' tool for living, architecture stands for the phenomenological-self because natural attitude of humans' mind often brings the phenomenological view into their being via how they survive and how they experience. Unlike philosophy, architecture is concrete with form, function, and meaning. It originates from human's experiences of the surrounding world and 
those of resilience to the future changes. In other words, architecture comes from simultaneously natural and rational projections of the experiences to the Earth and Heaven in-between. Making a dwelling means the phenomenological self carries out a historical journey to his needs and site essence, in which he is as a phenomenon dialogic with nature's phenomena for primitive, collective, and identical characteristics. The phenomenological self takes architecture in meaning of human incarnation as a phenomenon to infill the gap of its environment, where things are there, such as men, animals, plants and things. Architecture becomes the whole gathering things articulately, as the interweavement of rationality, naturalness, and historicity full of vitality of its place.

Martin Heidegger turned the phenomenological-self, as a thrown way in the world, into an emotional-self as a lonely-man, in Poetry, Language, Thought. The man used language as his objective voice in order to wish, to dream, and to depict his world. Phenomena, architecture one of those, thus hide in language. Understanding language reveals us about essence of building and dwelling. As dwellers listening to what language saying in bauendwell, "to remain, to stay in a place," (Martin Heidegger, "Building Dwelling Thinking," in Poetry, Language, Thought, Trans. and Intr. Albert Hofstadter. (New York: Harper \& Row, 2001), 144) we can hear "Building is really dwelling, being the manner, in which mortals are on the earth. Building as dwelling unfolds into the building that cultivates growing things and the building that erects buildings." (Ibid.,146). Architecture, as dwelling and buildering, appears in a form that opens a significant with the involvement in others on earth. Its building means to set up a world and the process of opening the world, at the same time, establishes the living world back again on the earth.

\subsection{The centripetal self}

\subsubsection{A perpetual man}

Merleau Ponty, on Phenomenology of Perception, translated the emotional self to the perceptual self. The self is being in the perceptual situatedness as the body subject into the world. Perception is human beings fundamental act and it motivates them to reside in space and time. More and more accessing into the inhabitance, the world is seen as perceived. The perception renders the experiences invisible and visible, consisting of 'reciprocal intersection and intertwining.' (Derya Yorgancioglu, "Steven Holl: A translation of phenomenological Philosophy into the Realm of Architecture," in Invitation to Archiphen: Some Approaches and Interpretations of Phenomenology in Architecture, ed. Iris Aravot\&Eran Neuman (Bucharest: Zeta books, 2010), 25.). One of well-known architects, Steven Hollexplored the concept of perceptual experiences to look for the essence of what the self thinks and what the self does. They range 'from the abstract to the concrete' (Ibid.). and from 'the unformed to the formed'. Holl believed in digging out the past to identify the real power of architecture or experiential power that makes architecture comes into the presence. In the journey of the excavation, the self-force, site-force, and phenomenal properties interact with each other and form abstract ideas. Gradually become concrete ideas, and they are transformed into materials, spatial and formal entities on a physical site.

\subsubsection{A wandering man}

Christian Norberg-Schulz transformed the lonely-man to the wandering-self that links to common and concrete things as given contents of our existence, or phenomena gathered as an environmental place for living, such as the whole including "people, animals, flowers, trees and forests, stone, earth, wood and water, towns, streets and houses, doors, windows 
and furniture, sun, moon, stars, drifting clouds, night and days, changing seasons, bridge, fountain, gate, jug, fruit," (Christian Norberg-Schulz, "Place," in Genius Loci: Towards a Phenomenology of Architecture (New York: Rizzoli, 1979), 6.). etc., even intangible things as feelings. Like emotional man, the wandering self is still the part of the phenomena unity. Buildings as spiritual phenomena of aimlessly wandering dwellers are connected to their environment by resting on the ground and rising towards the sky. The structure of their place is considered as landscape and settlement that constituted by spaces, characters and demonstrated by geometry. They follow the principles of orientation, centralization, proximity, and rhythm that a man cognized in the place.

\subsubsection{A sensory man}

Juhani Palassma evolved the emotional-self further to the sensory-self, on his famous work, The Eyes of The Skin. He experiences the world not only seeing but hearing, smelling, tasting, and touching. Only basing on vision, architecture is mesmerized into the flow of images without "focus and participation." (Juhani Palassma, "Hegemony of the eye and loss of the body," in Thesis: Ars Imitatur Naturam, Schirmer, ed. Heidemarie, and Dörte Kuhlmann. (Bauhaus-Universität Weimar: Universitätsverlag, 1998, 110).

The authenticity of architecture is based on the understanding simultaneously constructional acts of those senses. Similar to the lonely self, the experience self still is attached to place historicity through materiality and time. As the experiential place, architecture is the organization and articulation around the center as human body, because he "beheld, touch, listen, and measure the life-world via space and time with their entire bodily existence," (Ibid.,116) or called multi-sensory experience. Following this idea, Peter Zumthor architect developed his buildings as centers that gather seeing, smelling, tasting, sounding, and touching of their built environment that Swiss Pavilion "Sound Box" at Expo 2000 in Hanover, Germany, is the typical example.

\subsection{Phenomenology method in architectural practice}

Table 1. Ego types, place, and its features.

\begin{tabular}{|c|c|c|c|c|}
\hline \multicolumn{2}{|c|}{ The phenomenological self } & \multicolumn{3}{|l|}{ The centripetal self } \\
\hline A pure man & A being man & A perpetual man & A wandering man & A sensory man \\
\hline $\begin{array}{l}\text {-Existing as a } \\
\text { phenomenon } \\
\text {-Free from } \\
\text { prejudices for true } \\
\text { understanding via } \\
\text { investigation of } \\
\text { knowledge, } \\
\text { phenomenological } \\
\text { reduction, record } \\
\text { of forms variety, } \\
\text { grasp of } \\
\text { interweavement }\end{array}$ & $\begin{array}{l}\text {-Thrown away in } \\
\text { the living world, } \\
\text { filling up the gap } \\
\text { in-between earth } \\
\text { and heaven } \\
\text { - A part of the } \\
\text { whole } \\
\text { - Dweller as } \\
\text { builder }\end{array}$ & $\begin{array}{l}\text {-His existence as } \\
\text { an appearance } \\
\text { with } \\
\text { interconnected } \\
\text { relations } \\
\text {-Existence as the } \\
\text { center of the } \\
\text { visible and the } \\
\text { invisible, folded } \\
\text { and unfolded }\end{array}$ & $\begin{array}{l}\text { - Either his being } \\
\text { as a focus or a } \\
\text { participator in the } \\
\text { world } \\
\text {-And link to the } \\
\text { world through his } \\
\text { centralization, } \\
\text { orientation, } \\
\text { proximity, and } \\
\text { rhythm }\end{array}$ & $\begin{array}{l}\text {-Living in the } \\
\text { world with his } \\
\text { oblivious } \\
\text { memories } \\
\text {-The true world } \\
\text { appeared by his } \\
\text { apperception }\end{array}$ \\
\hline \multicolumn{5}{|c|}{ Place and its historical features } \\
\hline $\begin{array}{l}\text { Place as place } \\
\text { described as } \\
\text { interconnection, } \\
\text { diversity, and } \\
\text { trueness }\end{array}$ & $\begin{array}{l}\text { Dwelling as } \\
\text { building } \\
\text { constituted by the } \\
\text { wholeness, its } \\
\text { structure, and } \\
\text { landscape }\end{array}$ & $\begin{array}{l}\text { Place of } \\
\text { inhabitance } \\
\text { comprehended as } \\
\text { openness and } \\
\text { closeness, and } \\
\text { attachment and } \\
\text { intertwinement }\end{array}$ & $\begin{array}{l}\text { Settlement } \\
\text { assigned to its } \\
\text { space, time, and } \\
\text { remembrance }\end{array}$ & $\begin{array}{l}\text { Place ascribed to } \\
\text { interaction and } \\
\text { emotions }\end{array}$ \\
\hline
\end{tabular}


Phenomenology method brings the site's historical characteristics to architecture as the unity of form and function, in which designer plays a role as a centripetal self and a phenomenological self. The influence of the historicity makes form meaningful in its space and time. The concept of place is various, depending on the design self being a lonely man, a perpetual man, a wandering man, or a sensory man. The spirit of a place incarnates through its historical features as shown in Table 1, depending on building site circumstanced. In the process, the self's goal directs to the site historical source and receives all information for his existence meaning. The latter plays a role as method that filters all the facts from the historical survey to make sure them released from designer's prejudices and his demands. The method focuses on rules of intuition, essence, reduction, deduction, and variation to create selected structures that articulate to the present situations and adapt to future changes. Depending on the needs of meaning, form, and program, one of those would be selected for architectural appearance. The method is referred from the pure phenomenological-self five phases. In architectural practice, the phenomenological method can be established as in the illustration below,

a) Simultaneously carry out investigation and phenomenological reduction of a selected site,

b) Historically discover the place constitution and record geometrical interconnections and diversifications

d) Naturally receive essential intuition of the site and objectively describe shown-up form

e) Reflect and adjust the appearance for assimilation with its surrounding

\subsection{The example of phenomenological design}

The studio Arch 744- Workers Housing in Danang City, Vietnam was selected for all steps illustration. This project design was based on the phenomenological method and finished by a D.Arch group in Fall2015 semester at UHM, School of Architecture. All phases of phenomenology method were applied correspondingly to the project design as follows,

Investigating the project's place.

Following to its investor's requirement, the site locates on the new urban and side by side to the pond and sea. Its position is close to Hoa Khanh industrial zone and city center. It takes 10 minutes to walk to the factory area and 15 minutes to bike to the center. Architecturally, the building function is suggested to provide 2,000 housing for workers with 5 stories in height. According to social observation, workers mostly come from adjacent areas and provinces, where are still preserving traditional lifestyle of village community. Surrounding the site, there are new buildings built by government but are still empty because these modern spaces did not meet worker's village culture internal demand. More important, street atmosphere as the Danang cultural feature was not created in this area.

Because of its flat constitution, traditional culture as site historicity is recorded and transformed into making the place. To attract people for living, traditional lifestyle is determined for home inside and outside atmosphere. House structure comes up with units and stacks for shading and gardens. With variety of employee's situations, the house spaces include living space, bedroom space, bathroom space, dining room, and porches as storages and family community space. Virtually, all houses are adjacent for neighborhood communication. The primary parts of an apartment are front yard, back yard, worship space and front and back gardens for vegetables and ventilation. They result from strict weather of raining, storm, and sun season. To adapt to social aspect, three kinds of housing is offered, including one bedroom for single worker, two bedrooms for couple and their kid, and two bedrooms and one open bedroom for couple, their kid, and their parent.

Receiving intuition of the site essence and describing concept-out of form 
This place is crystalized by two senses of tradition and modern. Manifestation of modern spirit is street atmosphere, which is easy and convenient to access to and out building for living, market, gathering, and business. Manifestation of traditional spirit is home atmosphere, which is yards, porch, and gardens for neighborhood community and family plantation. All factors are articulated together with site forces that includes agriculture pond and sea power when flooding happens.

\subsection{Reflect and adjust the appearance for articulation}

Existing entrances and roof garden are added for emergency cases and thermal prevention. Space structure of units follows structure of traditional house for home atmosphere inside and. They are stacked and stepped back in each of stories to create street atmosphere outside (Figure 1). Accordingly, concrete framework is used for durability and economy, and bearing walls are placed at the stepped consoles, on lanais, for the framework support. The whole structures are also connected to the pond and the sea to make sure maintaining cultural and social habits of the population and workers as well. The building falls in the line of the site context because of its modern form, traditional structure, and environmental connection.

\section{Discussion}

Architectural design is a process of creativity in which fantasy (dream and visions), imagination (what is there, to perceive reality, to recreate or to repeat reality), and reality (buildings) coexist with each other. Fantasy engages primitive environmental memories. They play a role as a catalyst or a power for imagination and belong to the sphere of the mind. The memories produce being meaning for architectural form. Indeed, phenomenology method performs a journey to rediscovers the remembrance and on the processing, it records all events without experienced interpretations. The method directly performs the nature of designers' perception in making humans' place that encompasses site environment and its building. It brings out the reciprocal relation between building and built place, or human and nature. Also, different from other modern movements, the method makes structured form integrating to its surrounding as it is grown on earth. Though basically based on individual experience, the place is formed independent of subjectivity by means of site historicity. Rather, genius loci as the objectivity of the design manifests at the effect of site conformation that is shaped by space, time, and culture. The historical influence on architectural form, by investigation and transformation, depends on the different selves and site perceived characteristics. Unlike other studies, the paper provides a new approach and opens a new thinking of making meaning for architectural form. It shows that architecture is still the object characterized by human beings. Moreover, grounding on environmental historicity, the method helps to understand a genuine form that deeply roots in its place.

\section{Conclusion}

This research explores a culturally and environmentally responsive design method, or called historicity design method, that promises to meet the meaning demand in architectural form today. Phenomenological method examines into the being and digs out an architecture of immanent intuitions and local experiences. The method selected site as the primary material, as the whole, because it gathered all historicity of its existing in respect of space, time, geometry, interconnection, openness, closeness, attachment and surrounding, and can provide architectural form with high degree of articulation to the built environment. Through 
the phenomenological investigation, the study indicates that vertical and horizontal landscape is transformed into the form different from modern ones extremely abstract and rational.

\section{References}

1. D. Seamon, Dwelling, Seeing, and Designing: Toward a Phenomenological Ecology (State University of New York Press, Albany, 1993)

2. E. Husserl, The Idea of phenomenology, edited by Rudolf Bernet, translated by Lee Hardy (Kluwer Academic Publishers, Dordrecht, 1999)

3. E. Husserl, Cartesian Meditations: An Introduction to Phenomenology, translated by Dorion Cairns (Kluwer Academic Publishers, Netherlands, 1999)

4. M. Heidegger, Poetry, Language, Thought, translated by Albert Hofstadter (Harper \& Row, New York, 2001)

5. C. Norberg-Schulz, Genius Loci: Towards a Phenomenology of Architecture (Rizzoli, New York, 1979)

6. I. Aravot, E. Neuman, Invitation to Archiphen: Some Approaches and Interpretations of Phenomenology in Architecture (Zeta Books, Bucharest, 2010)

7. S. Heidemarie, D. Kuhlmann, Thesis: Ars ImitaturNaturam (Bauhaus-Universität Weimar, Universitätsverlag, 1998)

8. P. Shora, Current World Environment 10-1, 404-411 (2015)

9. E. Perez de Vega, International Journal of Arts \& Science 4-3, 45-48 (2011) 